\title{
-DUK Eki Ve Divânü Lûgati't Türk'te -DUK Ekli Görülen Geçmiş Zaman Çekimi
}

\section{Mehmet Vefa Nalbant*}

"Ekler, dil denen canlı organizmanın bir parçası olarak zaman içinde fonetik ve semantik değişmeye uğrayabilirler. Genellikle kalıplaşma ve kullanılış özelliği ile ortaya çıkan semantik değişmeler, dilin ifade imkânlarını genişletir. Geniş bir coğrafyada çok sayıda insan tarafindan konuşulan dillerde, bu hadiseler daha yaygındır. Türkçede de eklerdeki semantik değişmelerin sayısız örneklerini görüyoruz. Meselâ, Eski Türkçenin gelecek zaman eki “-ga / -ge”, Batı Türkçesinde hem fonetik yapısını değiştirmiş hem de gelecek zaman, geniş zaman, istek, emir bildiren çok fonksiyonlu bir ek hâline gelmiştir."'

Timurtaş'ın üzerinde durup örnek verdiği -ga / -ge eki gibi DUK eki de Türkçenin gelişim süreci içinde farklı işlevlerde kullanılmıştır. Türkçenin ilk dönem eserlerinden başlamak üzere yazılı tüm metinlerde kolaylıkla tespit edebildiğimiz bu ekin menşei nedir? Eski Türkçe döneminden itibaren bu ek tarihî lehçelerde nasıl bir gelişme seyri izlemiştir? -DUK eki bir fiil çekim eki olarak sadece I. çoğul şahıs ekinin çekiminde mi kullanılmıştır yoksa bu ek yapısında bulunan $o k$ edatının etkisiyle bütün şahıslar için kullanılan zaman eki + edat görünümündeki bir ek midir?

Bütün bu sorulara cevap verebilmek için önce bu ekin menşei konusunda yapılan değerlendirmeleri gözden geçirmek gerekmektedir.Bu ekin menşei konusunda bilim adamları farklı görüşler ileri sürmüşlerdir. Bu bilim adamlarından Brockelmann DUK ekini menşe olarak - $t$ fiilden isim yapma eki ile uk edatının birleşmesine bağlarken², Ramsted ve Kotwitcz ise -DUK ekini

\footnotetext{
*. AÜ Sosyal Bilimler Enstitüsü, Türk Dili ve Edebiyatı Ana Bilim Dalı Araştırma Görevlisi

1 Timurtaş, Faruk Kadri, Eski Türkiye Türkçesi, İstanbul Üniversitesi Yay., 2. baskı, İst. 1981, s. 126-128

2 Brockelmann, C.; Osttürkısche Grammatik Der Islamischen LitteraturSprachen Mittelastens, Leiden, 1954, s.261
} 
Moğolcadaki dag, Tunguzcada dig şekillerine dayandırmaktadırlar. Ramsted ekin sonunda görülen $/ k /$ fonemini DUK şeklinden getirir ve bu şeklin eski bir çokluk eki olduğundan söz eder. Ramsted bu açıklamalarının yanında $/ k$ /foneminin -sAK (şart), -DUK ( geçmiş zaman) ve-yuk (emir) şekillerinde bulunduğuna da dikkat çeker. ${ }^{3}$

Türkçedeki eklerin bitişim teorisine göre belirli bazı kelimelerden kısalma yoluyla oluştuklarını ileri sürüp, bu teori ışığında ekleri tahlil eden Kuznetsov, görülen geçmiş zaman ekleri DI ve-DUk eklerini tüke-filine dayandırmakta ve -DI ekinin-DUk ekinden geliştiğine inanmaktadır. Kuznetsov'un bu iki ek için yaptığı etimoloji şöyledir: tüke- $>t u ̈ k>t$. $^{4}$

-DUK ekinin menşei ile ilgili olarak yapılmış dikkat çekici açıklamalardan biri de Şinasi Tekin'e aittir. Tekin -ma olumsuzluk eki ve -DUK eki ile ilgili olarak kaleme aldığı yazısında bu eklerin kökenini Toharcaya dayandırmaktadır. Tekin'e göre -DUK eki Toharcadaki " ma te ok" biçiminden -maduk biçimine gelmiştir. Tekin'e göre ma te ok şekli, Eski Türk yazı dili teşekkül etmeden çok önce -ma-tı ok biçimine gelişmiş ve daha sonra sondaki ok pekiştirme edatı ekleşerek -maduk şekline girmiştir. Eski Türkçe döneminde -ma olumsuzluk edatı olarak tamamıla benimsenince maduk ekinden -duk müstakil bir ekmiş gibi tabii olarak ayrılmış ve olumlu fiil köklerine getirilerek bildiğimiz -DUK eki ortaya çıkmıştır.

-DUK ekinin kökeni ile ilgili bu görüşlerin ışığında ekin Eski Türkçeden başlamak üzere tarihî lehçelerdeki durumuna bakmak gerekmektedir:

Eski Türkçede fiil çekimini kuran bazı eklerin daima şekil ve zaman, bazılarının ise hem isim-fiil eki hem de şekil ve zaman eki olarak kullanıldığı görülmektedir (-DI, -AyIn, -Ar, -sAr vb.). Bazı

\footnotetext{
${ }^{3}$ Räsänen, M.; Materialien zur Morphologie der Türkischen Sprachen; Helsinki; 1957, s. 202-203

${ }^{4}$ Daha fazla bilgi için bkz: Kuznetsov, İ. Petro; "Türkiye Türkçesinin MorfoEtimolojisine Dair”, TDAY-Belleìen, 1995, s.193-262

${ }^{5}$ Daha fazla bilgi için bkz: Tekin Şinasi; Işstikakçının Köşesi, Türk Dilinde Kelimelerin ve Eklerin Hayatı Üzerine Denemeler, Simurg, 2001, s.43-58
} 
isim fiil eklerinin daha Eski Türkçe devresinde şekil ve zaman eki durumuna geçmelerinin sebepleri şunlardır: 1. İsim-fiil eklerinin hareket ifadesi taşıması 2. İsim fiil eklerinin zaman ifadesi taşıması. ${ }^{6}$

Kemal Eraslan geçmiş zaman ifadesi taşıyan, Türkçenin umumî isim-fiil eklerinden biri olan-DUK ekinin daima isim fiil olarak kaldığını, ancak görülen geçmiş zaman fiil çekiminin çokluk 1 . şahsına tesir ederek bu çekimi kendisine benzettiğini ifade etmiştir. ${ }^{7}$

Ek Eski Türkçede sıfat, isim ve yüklem ismi teşkil etmiştir. ${ }^{8}$

1.sıfat olarak kullanılmıştır.

Kut bulmaduk midik tınliglar

Öñre kisre işitmedük at

2. İsim olarak kullanılmıştır.

\section{Burhan kutıña katığlantuklarınta}

\section{Teñri küç birtük üçün}

3.Yüklem İsmi olarak kullanılmıştır.

\section{Sekiz oguz tokuz tatar kalmaduk}

\section{Karluk işiñe kelmedük}

Eski Türkçede kesin geçmiş zaman çekiminde -DUK şekline rastlanılmamaktadır. Bunun yerine DI + şahıs zamiri şeklindeki çekim şekli kullanılmıştır. Eski Türkçe dönemi eserlerinde bu zamanın çekimi şöyledir. 1.tekil şahıs $\{-D X m\}, 2$ tekil şahıs $\{-D X \tilde{n}$

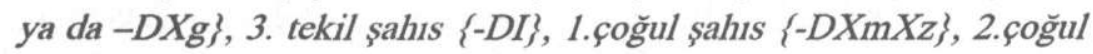

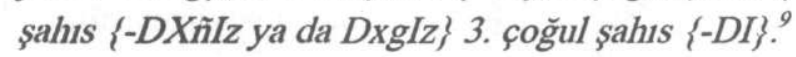

\footnotetext{
${ }^{6}$ Eraslan, Kemal; Eski Türkçede İsim-Fiiller, İstanbul Üniversitesi Edebiyat Fakültesi Yay., İstanbul, 1980, s. 153

${ }^{7}$ Eraslan, Kemal; age, s. 26

${ }^{8}$ Gabain, A. Von; Eski Türkçenin Grameri, Çeviren: Mehmet Akalın; TDK Yay., Ankara, 1988, s.82

'Daha fazla bilgi için bkz: Tekin, Talat; Orhun Türkçesi Grameri, Simurg Yay., Ankara, 2000, s.182-185; Talat Tekin Kitabının ikincil son biçimler başlıklı bölümünde $\{-\mathrm{DOk}\}$ ekli geçmiş zaman ekinden bahsetmekte ve bu
} 
-DUK eki Karahanlı Türkçesi sahasında çok işlek bir ek değildir. $\mathrm{Bu}$ ek bu dönem eserlerinde genellikle sıfat fiil eki olarak kullanılmıștır. Bu ekin fiil çekim eki olarak kullanımına sadece DLT'de rastlanılmıştır. (Ekin DLT'de fiil çekim eki olarak kullanılmasına ilişkin açıklamalar yazımızın ilerleyen bölümlerinde yer almaktadır.)

Karahanlı Türkçesi dönemi eserlerinde -DIk ekinin ilk ünsüzü sedalılık- sedasızlık uyumuna uyar. İki ünlü arasında $/ \mathrm{k} /$ fonemi ise sedalılaşmaz:

\section{Munu men me emdi saña keldüküm}

\section{Meniñ ḳlḳm erdi bu körkittüküm $(\mathrm{KB}, 659)$}

Karahanlı Türkçesi döneminde görülen geçmiş zaman çekimi (DLT'de görülen ve Oğuz grubu lehçeleri için verilmiş -DUK ekli örnekler dışında) şu şekildedir:

I.tekil șahıs $\{-D X m\}, 2$ tekil șahıs $\{-D X \tilde{n}\}$, 3.tekil șahıs $\{-D I\}$, I.çokluk şahıs \{-DXmXz\}, 2. çokluk şahıs \{-DIñIz\}, 3.çokluk şahıs $\{-D I \text { ya da -DIIAr }\}^{\prime \prime}$

Harezm Türkçesi eserlerinde -DUK ile yapılan fiilden isim Rabguzi'de sık sık, Nehcü'l-Feradis'te ise seyrek görülür: saña ne ma'lum boldı anıñ uçtmahlıg erdüki (NF 239:7), ḳlduḳum işlerniñ tevili. $^{\prime \prime}$

Harezm Türkçesi eserlerinde görülen geçmiş zaman ekleri Karahanlı Türkçesi eserlerinde olduğu gibidir. Karahanlı Türkçesi ile Harezm Türkçesi arasında görülen geçmiş zamanın çekimindeki en önemli ayrılık Harezm Türkçesi eserlerinde 1. çokluk şahıs çekiminde -DImIz şeklinin yanında -DUK şeklinin kullanılmaya başlamasıdır.

eki almış eylem adlarının (3.tekil ve çoğul kişide) yüklem olarak kullanıldığını ifade etmektedir. Tekin bu ekin bir örnekte de 1. tekil kişi için kullanıldığını da söylemektedir. bkz. Tekin, Talat; s. 185

10 Hacıeminoğlu, Necmettin; Karahanlı Türkçesi Grameri, TDK Yay, Ankara, 1996, s. 184-185. Ayrıca bkz: Mansuroğlu Mecdut; "Karahanlıca", Tarihi Türk Siveleri, TKAE Yay., Ankara, 1979, s. 141-182

" Eckmann, Janos; "Harezm Türkçesi", Tarihi Türk Şiveleri, TKAE Yay., Ankara, 1979, s. 183-223 
-DUK Eki ve Divânü Lûgati't-Türk'te

-DUK Ekli Görülen Geçmiş Zaman Çekimi

Bugünkü Doğu şivelerinin kaynağı durumunda bulunan Çağatay Türkçesinde -DIK sıfat-fiil eki nadir kullanılmış, daha çok GAn sıfat-fiil eki ve bu ekle başka unsurların birleşmesiyle meydana gelen zarf-fiil ekleri tercih edilmiştir. -GAn sıfat-fiil eki de, -DIK sıfat-fiil eki gibi iyelik eki alır ve son çekim edatları ile kelime grubu meydana getirir. ${ }^{12}$

Çağatay Türkçesinde görülen geçmiş zaman ise kök ve gövde $+\mathrm{d}$ zaman işareti + iyelik eklerinden türemiş şahıs ekleri ile yapılır. Çağatay Türkçesinde bu zamanın çekimi şöyledir:

Aldım / aldıñ / ald $ı$

Alduk / aldıñz / aldılar ${ }^{\prime 3}$

Kıpçak Türkçesinde "bu ek geçmiş zaman sıfat-fiilidir. Zamanla görülen geçmiş zaman 1. şahıs çokluk şekliyle karışmıştır. Kıpçakça eserlerde sıfat-fiil olarak kullanılışına az rastlanılmaktadır. EH'da geçen -dükçe ve -dığından (< -dık-1-n-da) şeklinde olanlar yazar tarafından, geçmiş zaman fiil şeklinin sonuna gelen -kçe ve gı̀nda şekilleri olarak tasavvur edilmiştir." ${ }^{14}$

Keldükçe (EH, 153), kuyaş battığında kelge-men $(\mathrm{EH}, 153)$ vs.

Kıpçak Türkçesinde görülen geçmiş zaman ise şu şekilde çekimlenmektedir:

Tekil şahıslar: 1. şahıs -m (-men), 2.şahıs -ñ, 3. şahıs-dı

Çoğul şahıslar: I. şahıs $-k,-k,(-\dot{g},-b i z /-m i z,-k l e r), 2$. şahıs $\tilde{n ̃ z} /$-ñiz/-ñuz/-ñüz (-ñizler), 3. şahıs -lar/-ler

Aldım, aldıñ, aldı, aldık / alduk / çızdı́g /, aldıñız, aldılar ${ }^{\text {ss }}$

12 Özkan, Nevzat; “-DIk Sıfat-fiil Ekinden Yapılmış Zarf-fiil Ekleri Ve Gagavuz Türkçesi'nde Bir Zarf Fiil Eki: -DıcAAn (An)”, 3. Uluslar Arası Türk Dil Kurultayı, 1996, TDK Yay., Ankara, 1999, s.891-900

13 Eckmann, Janos; Çağatayca El Kitabı, Çeviren: Günay Karaağaç, İstanbul Üniversitesi Yay., İstanbul, 1988, s. 120

14 Karamanlıŏlu, Ali Fehmi; Kıpçak Türkçesi Grameri; TDK Yay., Ankara , 1994, s. 142

${ }^{15}$ Karamanlıoğlu, Ali Fehmi; age, s. 120-122 
Yukarıda da görüldüğü gibi -DUK eki, Eski Türkçe ve Karahanlı Türkçesinde (DLT hariç ) sadece sıfat fiil olarak bazı görevlerle kullanılmış görülen geçmiş zaman çekiminde kullanılmamıştır. Harezm Türkçesi eserlerinden başlamak üzere bu ek bir sıfat-fiil eki olarak I. çoğul şahıs görülen geçmiş zaman ekinin çekiminde kullanılmış ve gittikçe yaygınlaşmıştır.

Genel değerlendirmesini yaptı̆̆ımız bu ekin Karahanlı Türkçesi eserlerinden Divânü Lûgati't Türk'te farklı bir durumu vardır. Bu ek Divanda görülen geçmiş zaman eki olarak farklı bir özellik göstermektedir. Kaşgarlı Mahmut, kendi eserinde bu ek için bazı açıklamalarda bulunmuştur: "Çine varıncaya dek Uygur, Argu, Çiğil, Yağma, Toxsı gibi Türk boylarının büyük bir kısmı mazi sıygasının s ve ${ }_{\varsigma}$ ile bağlı olmasında birleşmişlerdir. Bunlar mazi sıygasında bard $ı$ derler. Suvarlarla Kıpçaklardan bir takımları ile Oğuzlar onlardan ayrilmışlardır. Bunlar $s$ yerine 11 yahut $\xi$, yahut tok kelimelerde 1 li yahut ince ahenkli kelimelerde 4 getirirler. $B u$ dilde müfret ve cemi sıygası bir olur, araları ayırt edilmez.

ق lı kelimelerde ya kurduk denir. "O yay kurdu demektir". “Men ya kurduk” denir ki "Ben yay kurdum” demektir. Biz ya kurduk "Biz yay kurduk".

غ lı kelimelerde ol süt saǵduk denir. "O süt sağdı" demektir, yine böyle olar tag̣ka aǵduk denir ki” Onlar dağa ağdılar” demektir.

Tok harfli kelimelerde ol anı urduḳ denir ki "O onu dövdü" demektir. Men munda turduk sözü de böyledir, "Ben burada kaldım." demektir.

ل li kelimelere örnek: "ol keldük, biz keldük, olar ewge kirdük" denir ki, "O geldi, Biz geldik, Onlar eve girdiler” demektir.

Çekmeli (imaleli) kelimelerde "men añar tawar berdük", “Men yarmak terdük" denir ki "Ben ona para verdim", “ Ben para topladım" demektir. Gördüğün gibi burada müfretle cemi arası ayrılmamıştır. 
-DUK Eki ve Divânü Lûgati't-Türk'te

-DUK Ekli Görülen Geçmiş Zaman Çekimi

Oğuzların birçoğu birinci şahsın birinci sıygasında öbür Türklerin bardım dedikleri yerde yerine ق getirerek barduk derler; müfretle cemi arasını ayırmazlar, yalnız öbür Türklerle, kendisine haber verilen mazi sıygasında birleșirler ve "gitti", "geldi" yerine barduk keldük demezler. ${ }^{16}$

Kaşgarlı'nın verdiği örneklerden, bir kısım Türk boylarının görülen geçmiş zaman çekimini farklı şekilde yaptıkları anlaşılmaktadır. Bu örneklerden hareketle -DUK ile çekimlenen şahıslar şöyle sıralanabilir.

Tekil şahıslar:

1.şahıs: men ya kurduk / men munda turduk /men añar tawar berdük / men yarmak terdük

2.şahıs: Bu şahıs için örnek verilmemiştir.

3.şahıs: Ya ḳurduḳ / Ol süt saǵduk / Ol keldük / Ol anı urduk

Çoğul Şahıslar:

1.şahıs: Biz ya ḳurduk / Biz aǵgduk / Biz keldük

2.şahıs: $\mathrm{Bu}$ şahıs için örnek verilmemiştir

3. şahıs: Olar taǵka aǵduk / Olar ewge kirdük

- Kaşgarlı'nın verdiği bu örneklerden şu sonuçlar çıkmaktadır:

1. -DUk eki Oğuz grubu lehçelerine ait bir ektir. Fakat Kaşgarlı'nın geçmiş zaman için saymış olduğu özellikler , XI. yüzyıl sonrasına giren Oğuzca metinlerle hiçbir şekilde tanıklanmadığı için, Oğuzcanın XI. yüzyıldan sonraki gelişiminde, bu özelliklerin yazı dilini etkilemediği anlaşılmaktadır. ${ }^{17}$

2. -Duk şekli Oğuz grubu lehçelerinin hemen hepsinde ve (II. Şahıslar hariç) bütün şahıslarla kullanılmıştır. Kaşgarlı'nın da ifade

${ }^{16}$ Kaşğarlı Mahmud; Divânü Lûgati't -Türk, Çeviren: Besim Atalay, TDK Yay., Ankara, 1992, C II, s. 60-61

17 Korkmaz, Zeynep; "Kaşgarlı Mahmud Ve Oğuz Türkçesi”, Türk Dili Üzerine Araştırmalar, TDK Yay., Ankara, 1995, s. 241-253 
ettiği gibi bu zamanın çekiminde yukarıda adı geçen Türk boyları teklik ve çokluğu ayırmazlar. Bu durum yazımızın başında ekle ilgili olarak verdiğimiz etimolojik tahlillerde yer alan ve -DUk ekinin yapısını oluşturan unsurlardan biri olan $O k$ edatının $(-D I+o k)$ bir etkisi olarak değerlendirilebilir. Ekin bütün şahıslarla çekimlenmesi ve çekimde belirleyici olarak eklerin değil zamirlerin kullanılması da Ok edatının çekime bir etkisi olarak düşünülebilir. ${ }^{18}$

3. Bu ek Oğuz grubu Türk lehçelerinde önce bütün şahıslarla kullanılmış fakat Harezm Türkçesi dönemi eserlerinden başlamak üzere görülen geçmiş zaman I. çoğul şahıs eki olarak genelleşmiştir.

4. $O k$ edatının Eski Türkçe'de birer zarf-fiil olarak da kullanılan ve yine Eski Türkçe'de şartın çekiminde DLT'den -DUK ile ilgili alınmış örneklerde olduğu gibi şahıs eki almayan ve şahsın zamirlerle belirlendiği -sa(Eski Türkçede $-\mathrm{sAr})^{19}$ ve yine Eski Türkçe'de aynı zamanda zarf -fiil olarak kullanılan - $\mathrm{d}_{1}$ ekine ${ }^{20}$

18 -DUk ekinin bütün şahıslarda kullanılması ve yapısında bulunan ok edatı bu ekin oğuz grubu lehçelerinde şahıs fonksiyonunu yitirmiş ve edatlaşmış bir ek olma ihtimalini düşündürmektedir. Nitekim Türkçe'de şahıs eki olarak düșünülen bazı eklerin (Emir ikinci teklik şahıs eki - gıl )aslında birer edat oldukları bilim adamları tarafından ortaya konmuştur. $\mathrm{Bu}$ konuda bkz: Osman Fikri Sertkaya, "Bolsungıll Tep Tediler", Uluslar Arası Türk Dili Kongresi, 1988, Bildiriler, TDK Yay., Ankara, 1996, s. 135-142

19) Görülen geçmiş zamanın I.çoğul şahsında -DUk ekinin ilk önce Harezm sahasında görülmesi gibi (DLT Hariç), şartın I.çoğul şahsında görülen sak'lı șekiller de ilk olarak Harezm sahası eserlerinde tespit edilmiştir.

${ }^{20}$ Leylâ Karahan -dı / -di eklerinin bir zarf fiil olarak kullanıldığını ve hiçbir şahıs eki almadan, şahıs ve kip ifadesi taşımadan, içinde bulunduğu kelime ve kelime grubunu cümlenin yüklemine bağladığını dile getirmektedir. Leyla Karahan Köktürkçe ve Karahanlı sahasından bu durumla ilgili olarak şu örnekleri vermektedir: Tört buluñdaki budunug kop baz kıldım yagısız kıldım kop maña körti ișig küçi birür (Dört taraftaki milleti hep tabi kıldım, düșmansız kıldım, Hep bana tabi olup iși gücü berir.) Kültigin, Doğu-10. Ular ḳuș ünin tüzdi ï̈nder ișin (Keklik, sesine ahenk verip eșini çağırdı. ) Kutadgu Bilig Bilgi için bkz. Karahan, Leylâ; "Görülen Geçmiş Zaman Eki -DI/ -Di'nin Tarz Ve Bağlama Fonksiyonuna Dair'Türk Kültürz̈ Araștumaları Dergisi, 28, 1-2,1998, s. 335-341 
-DUK Ekli Görülen Geçmiş Zaman Çekimi

gelmesi, bu eklerin arasındaki paralelliği ve ok edatının işlev olarak birbirine yakın eklere geldiğini gösterir. -DUk ekinin gerek zarf-fiil olarak gerek şahıs eki olarak kullanımında şart ekine benzerliği, ok edatının her iki ekle (çekimde hem şart hem de -DUK ekleriyle kullanılır) de kullanılması, -DUK şahıs ekinin -sAr şart ekinde olduğu gibi zarf fiil eki olạrak da kullanılabilen *DI zaman eki ile + ok edatından oluştuğunu düşündürmektedir.

\section{KAYNAKÇA}

Arat, Reşit Rahmeti, Kutadgu Bilig, Metin-I, TDK Yay., 3. bask1, Ankara, 1991

Banguoğlu, Tahsin; Türkçenin Grameri, TDK Yay., 4. Baskı, Ankara, 1995

Brockelmann, C.; Osttürkısche Grammatik Der Islamischen Litteratur-Sprachen Mittelasiens, Leiden, 1954, s.261

Dankoff, R., Kelly, J.; Compendium Of The Turkıc Dialects, C. I, II, III, Harvard Üniversitesi Basımevi, 1982

Eckmann, Janos; Cağatayca El Kitabı, Çeviren: Günay Karaağaç, İstanbul Üniversitesi Yay., İstanbul, 1988 Ankara, 1979

Eraslan, Kemal; Eski Türkçede Ísim-Fiiller, İstanbul Üniversitesi Edebiyat Fakültesi Yay., İstanbul, 1980, s. 153

Ercilasun, Ahmet Bican; Kutadgu Bilig Grameri-Fiil, Gazi Üniversitesi Yay., Ankara, 1984

Ergin, Muharrem; Türk Dil Bilgisi, Bayrak Yay., 19. Baskı, İstanbul, 1990

Gabain, A. Von; Eski Türkçenin Grameri, Çeviren: Mehmet Akalın; TDK Yay., Ankara, 1988, s.82 
Hacıeminoğlu, Necmettin; Karahanlı Türkçesi Grameri; TDK Yay, Ankara, 1996,

Karahan, Leyla; “Görülen Geçmiş Zaman Eki -DI/ -DI'nin Tarz Ve Bağlama Fonksiyonuna Dair", Türk Kültürü Araştırmaları Dergisi, $28,1-2,1998$, s. $335-341$

Karamanlığlu, Ali Fehmi; Kıpçak Türkçesi Grameri; TDK Yay., Ankara, 1994, s. 142

Kaşğarlı Mahmud; Divânü Lûgati't-Türk, Çeviren: Besim Atalay, TDK Yay., Ankara, 1992

Korkmaz, Zeynep; "Kaşgarlı Mahmud Ve Oğuz Türkçesi”, Türk Dili Üzerine Araştırmalar, TDK Yay., Ankara, 1995, s. 241-253

Kuznetsov, İ. Petro; "Türkiye Türkçesinin MorfoEtimolojisine Dair", TDAY-Belleten, 1995, s.193-262

Mansuroğlu Mecdut; "Karahanlıca", Tarihi Türk Siveleri, TKAE Yay., Ankara, 1979,

Osman Fikri Sertkaya, "Bolsungiı Tep Tediler", Uluslar Arası Türk Dili Kongresi, 1988, Bildiriler, TDK Yay., Ankara, 1996, s. 135142

Özkan, Nevzat; "-DIk Sıfat-fiil Ekinden Yapılmış Zarf-fiil Ekleri Ve Gagavuz Türkçesi'nde Bir Zarf Fiil Eki: -DicAAn (An)”, 3. Uluslar Arası Türk Dil Kurultayı, 1996, TDK Yay., Ankara, 1999, s.891-900

Räsänen, M.; "Materialien zur Morphologie der Türkischen Sprachen", Helsinki, 1957, s. 202-203

Tekin Şinasi; İstikakçının Kössesi, Türk Dilinde Kelimelerin ve Eklerin Hayatı Üzerine Denemeler, Simurg, 2001

Tekin, Talat; Orhun Türkçesi Grameri, Simurg Yay., Ankara, 2000

Timurtaş, Faruk Kadri, Eski Türkiye Türkçesi, İstanbul Üniversitesi Yay., 2. baskı, İst. 1981, s. 126-128 
-DUK Eki ve Divânü Lûgati’t-Türk'te

-DUK Ekli Görülen Geçmiş Zaman Çekimi

\section{Kısaltmalar}

DLT: Divânü Lûgati't Türk

KB : Kutadgu Bilig

Yay. : Yayınları

TDK : Türk Dil Kurumu

TKAE : Türk Kültürünü Araştırma Enstitüsü 